\title{
A New Smart Web Platform for Plastic Injection Molds in Industry 4.0 Environments
}

\author{
Cristina Martin-Doñate ${ }^{1(\otimes)}$, Sliman Shaikheleid ${ }^{2}$, Abelardo Torres-Alba $^{1}$, \\ and Jorge Manuel Mercado-Colmenero ${ }^{1}$ \\ ${ }^{1}$ Department of Engineering Graphics, Design and Projects, University of Jaén, \\ Campus Las Lagunillas, s/n, 23071 Jaen, Spain \\ cdonate@ujaen.es \\ 2 Fakultät Mechanical and Medical Engineering, Hochschule Furtwangen University, \\ Campus Villingen-Schwenningen, Schwenningen Jakob-Kienzle-Strasse 17, \\ 78054 Villingen-Schwenningen, Germany
}

\begin{abstract}
This paper presents a new smart web platform for plastic injection molds for use in industry 4.0 environments. The new platform requires as its only input the CAD model of the plastic part in a discrete format, the accuracy of the analysis, the thermoplastic material of which the part will be manufactured and the number of parts to manufacture per year. Using this information and through a fully automated process based on hybrid algorithms developed by the authors the smart platform generates an extended CAD model of the mold with additional expert information useful for industry 4.0 environments. In this way, it is possible to design a mold with uniform heat transfer, balanced ejection and a uniform filling phase of the mold cavity. The presented platform differ from other applications for mold designing in that the resulting mold meets all the geometric, functional and technological requirements of mold designing without needing CAE simulation software for its validation. The presented platform is considered as the first smart platform that does not require the interaction of the designer in the process of dimensioning and designing the different subsystems that compound the mold, being a tool to reduce time and costs in the initial phases of plastic part design and with the ability to integrate into a flexible manufacturing environment 4.0.
\end{abstract}

Keywords: Smart manufacturing · Industry $4.0 \cdot$ Injection molding $\cdot$ CAD

\section{Introduction}

Nowadays, plastic injection molding is the most widespread manufacturing method in the industry $[1,2]$. With a conventional approach injection mold design is still performed empirically, based on the experience of the mold designer. The dimensioning tasks of the different mold components are highly dependent upon the knowledge of how the different geometrical and technological mold parameters interact with each other. In addition, mold designing requires highly qualified engineers from different disciplines. CAD designers deal with the dimensioning and modeling of each part, technicians in 
rheological simulation validate mold design in terms of time cycle and part quality, and mechanical engineers ensure the structural integrity of the mold. On the other hand, in order to design and simulate the mold each designer requires specific software which the company must acquire. Due to diversified complications of mold design with mold manufacturing and the coupling effects of plastic with molding machine, it is quite difficult to consistently molding the products with higher quality and precision. Even with high-end commercial software and hardware, the seamless integration of mold design, mold manufacturing and molding process needs innovative thinking [3]. Cyberphysical systems in industrial processes are characterized by their ability to connect the physical devices that compose it with ICT systems capable of accessing and processing the set of technological data obtained from the process.

This paper presents a new smart application integrated into a web platform. The new application differs from other mold designing applications in that it only requires the CAD model of the plastic part in a discrete format, the precision of the analysis, the thermoplastic material of the plastic part and the number of parts to be manufactured per year as application inputs. With only this information, and through a fully automated process based on the use of several hybrid algorithms developed by the authors, the platform generates a complete CAD design of the injection mold associated with the plastic part under analysis. The set of developed algorithms are compound of a first phase of automated recognition of the plastic part surface and a second phase of expert optimization for mold dimensioning. As a result the mold design meets the geometric, technological and functional requirements being capable of guaranteeing an adequate and accurate manufacture of the plastic part. The application provides in a few minutes a standard CAD design in parametric format of the injection mold. The smart application is valid for any CAD format in which the plastic part has been modeled since it works in a discrete format. On the other hand, the algorithms for obtaining the mold designing can be applied in any CAD system, being independent of the model and the modeler. Thus, the presented application differs from other software linked to the CAD format of the model which requires access to the internal information of the part. The new platform is the first one capable of working completely autonomously and intelligently, performing the complete process of optimal dimensioning and mold design without requiring, at any time, mold designer interaction during the process. Furthermore, the design of the resulting mold does not require numerical simulations for functional validation, since the expert calculation algorithms incorporate technological requirements that guarantee the correct performance of the mold. The application is designed for future implementation in an Industry 4.0 system that allows analyzing the deviations in the manufacturing parameters of the product.

\section{Methodology}

\subsection{Architecture of the Injection Molding Smart Platform}

The injection molding smart platform is structured in two large blocks. The first block of the platform consists of the implementation of four geometric-expert algorithms [4-7] responsible for analyzing the geometric demoldability of the plastic part in an automated 
way as well as dimensioning and positioning the set of elements that constitute the feeding system, the system of cooling and the ejection system of the mold. The architecture of the algorithms is structured in two different stages: The first geometrical stage is in charge of recognizing in an automated way the topology of the plastic part, obtaining information of the geometric parameters necessary for the optimal dimensioning of the mold.

A second expert stage optimizes the different elements that constitute the three main systems of the mold (cooling, ejection and feeding), using genetic optimization algorithms. Finally, the platform connects the resulting expert variables with the algorithm responsible for optimally dimensioning the structural and mechanical elements that constitute the mold. This means that the mold obtained allows uniform heat transfer between the plastic part and the coolant fluid, balanced ejection of the plastic part from the mold and an equilibrated filling phase of the injection mold cavities. This fact differentiates the presented platform from other mold design applications since the methodology accomplishes geometrical, functional and technological requirements of the mold, independently of the additional use of CAE simulation software.

Figure 1 shows a block diagram of the different algorithms that compose the web platform. This uses as input data the discrete geometry of the plastic part, allowing a total independence of the CAD modeler in which the plastic part has been designed. In contrast to other applications, the new application does not require additional information or designer interaction during the analysis process, dimensioning and designing the mold in a fully automated process.

The presented platform incorporates four databases with information about technical characteristics of thermoplastic materials, standard components of injection molds, technical characteristics related to the injection manufacturing process such as the characteristics of the coolant fluid and a data base with information related to the injection machines. Figure 2 shows a logical operation scheme of the smart web platform, including the phase of data processing introduced by the user, the phase of calculation of the results from the input data, the phase of designing and executing the algorithms and the phase of management of the stored information in the databases.

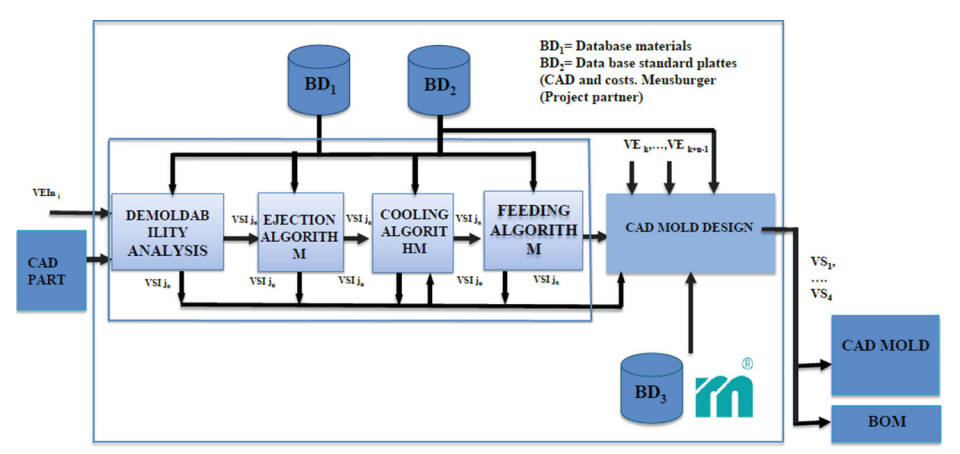

Fig. 1. Integration of the different geometric-expert algorithms of the smart web platform. 


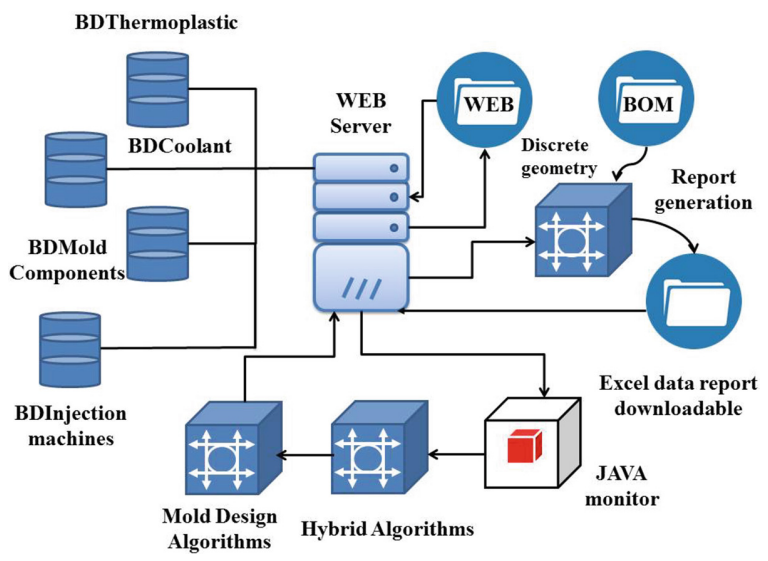

Fig. 2. Logical diagram of the functioning of the smart web platform.

\section{Results}

The injection molding smart platform generates a technological report that includes the results obtained for each geometric-expert hybrid algorithm [4-7, 8] and, in turn, the CAD modeling of the injection mold with the assembly of the elements which comprise it. The geometry of the study case and the result of the algorithm of the demoldability analysis is shown in Fig. 3a. As can be seen, the case study requires of two longitudinal slides along the $\mathrm{X}$ and $\mathrm{Y}$ coordinate axes for its manufacture. Figure $3 \mathrm{~b}$ shows the location on the ejection map of the ejection points of the plastic part. Figure $3 \mathrm{c}$ shows the distribution of the cooling channels on the geometries of the plastic parts under study. The cooling system design obtained by the presented platform is dimensioned under three conditions: obtaining a uniform distribution of the exchange of heat flow between the melt plastic flow and the cooling system, guaranteeing that the difference between the heat flow provided by the melt plastic flow and the heat evacuated by the cooling system is zero and maintaining the cooling flow throughout the cooling system in turbulent conditions. In order to validate the final quality of the plastic parts of the case studies and the sizing and design of the cooling system. Figure $3 \mathrm{~d}$ shows the results of the algorithm for the location of the injection point for each study case presented. Finally, Fig. 4a shows the temperature map after the cooling phase for each one of the plastic parts of the study. The temperature map of the plastic parts is uniform and homogeneous. It is thus demonstrated that the cooling quality, of the results obtained by this algorithm, is high. Figure $4 \mathrm{~b}$ shows the CAD model of the injection molds of the plastic parts under study. 

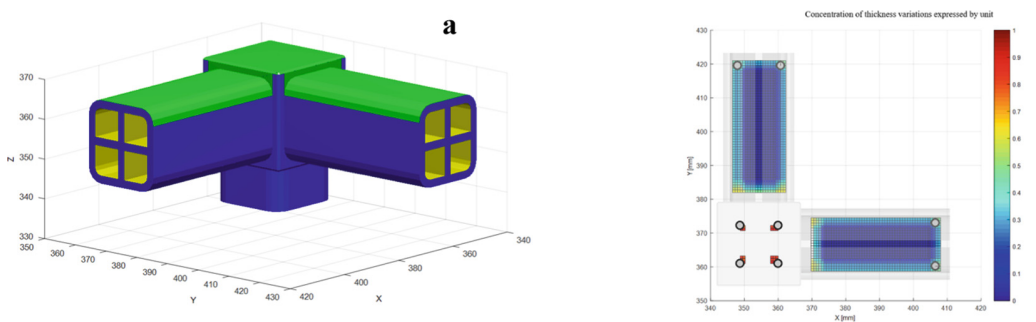

b

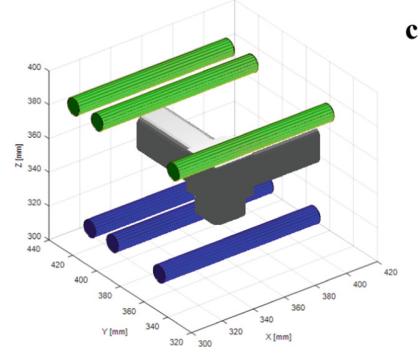

c

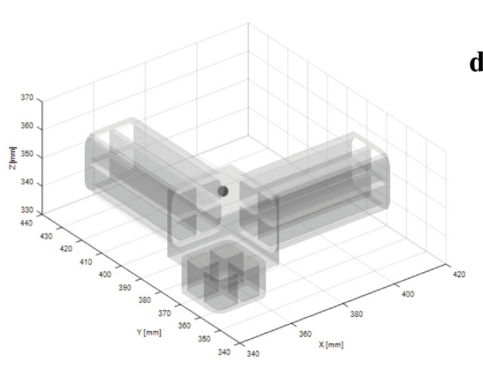

Fig. 3. a Demolding algorithm. b Design and dimensioning algorithm of the ejection system, c design and dimensioning algorithm of the cooling system, $\mathbf{d}$ location of the injection point

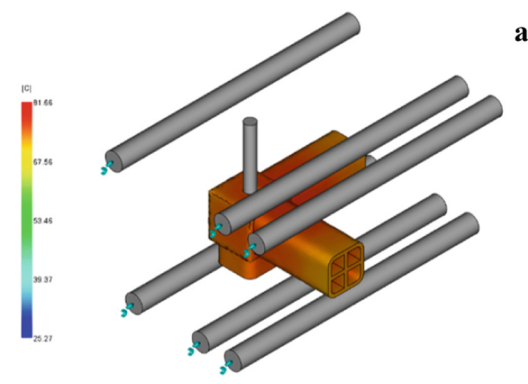

a

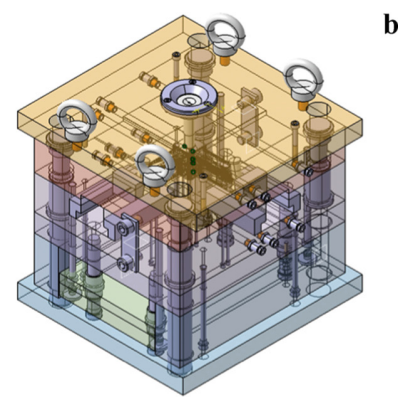

b

Fig. 4. a Results of the numerical simulation of the cooling, $\mathbf{b}$ CAD model of the injection mold

\section{Conclusions}

The work presented in this document shows a new smart web platform for the automated design of plastic injection molds based on geometrical-expert optimization algorithms. The presented smart platform has been tested through its application to a plastic part obtaining in a fully automated way a CAD model of the mold to manufacture the plastic part. The results obtained are presented as a basis for the implementation of a 4.0 platform in the molding industry.

The presented injection molding smart platform improves the mold design applications used up to now, since the resulting mold fulfills all the geometrical, functional and technological requirements of the mold independently of the use of CAE simulation software. Unlike other applications, it does not require additional information or the interaction of the designer during the process of analysis, sizing and design of the mold. 
The new platform is valid for any CAD format in which the plastic part has been modeled, since it works in a discrete format. It functions independently of the CAD modeler used to model the plastic part and without requiring access to the internal geometric information of the part to be analyzed.

Acknowledgments. This research work was supported by the University of Jaen through the Plan de Apoyo a la Investigación 2019-2020-ACCION1 PAIUJA2019-20: TIC-159.-Research stay Cristina Martin-Doñate Fakultät Mechanical and Medical Engineering-Hochschule Furtwangen University. 2019.

\section{References}

1. Martin-Doñate, C., Rubio Paramio, M.A.: New methodology for demoldability analysis based on volume discretization algorithms. Comput. Aided Design 45(2), 229-240 (2013)

2. Torres-Alba, A., Mercado-Colmenero, J.M., Diaz-Perete, D., Martin-Doñate, C.: A new conformal cooling design procedure for injection molding based on temperature clusters and multidimensional discrete models. Polymers 12(1), 154 (2020)

3. Jong, W.R., Chen, S.C., Wang, S.M., Liu, S.H., Liao, H.L., Ting, Y.H., Chen, H.T.: The implementation of cloud platform for injection molding process. Procedia CIRP 63, 219-223 (2017)

4. Mercado-Colmenero, J.M., Paramio, M.A.R., Perez-Garcia, J.M., Martin-Doñate, C.: A new hybrid method for demoldability analysis of discrete geometries. Comput. Aided Design 80, 43-60 (2016)

5. Mercado-Colmenero, J.M., Rubio-Paramio, M.A., Karlinger, P., Martin-Doñate, C.: A new procedure for calculating cycle time in injection molding based on plastic part geometry recognition. Int. J. Adv. Manuf. Technol. 98, 441 (2018)

6. Mercado-Colmenero, J.M., Muriana, J.A.M., Paramio, M.A.R., Martín-Doñate, C.: An automated manufacturing analysis of plastic parts using faceted surfaces. In: Eynard, B., Nigrelli, V., Oliveri, S., Peris-Fajarnes, G., Rizzuti, S. (eds.) Advances on Mechanics, Design Engineering and Manufacturing. Lecture Notes in Mechanical Engineering. Springer, Cham (2017)

7. Mercado-Colmenero, J.M., Rubio-Paramio, M.A., de Juanes Marquez-Sevillano, J., MartinDoñate, C.: A new method for the automated design of cooling systems in injection molds. Comput. Aided Design 104, 60-86 (2018) 
Open Access This chapter is licensed under the terms of the Creative Commons Attribution 4.0 International License (http://creativecommons.org/licenses/by/4.0/), which permits use, sharing, adaptation, distribution and reproduction in any medium or format, as long as you give appropriate credit to the original author(s) and the source, provide a link to the Creative Commons license and indicate if changes were made.

The images or other third party material in this chapter are included in the chapter's Creative Commons license, unless indicated otherwise in a credit line to the material. If material is not included in the chapter's Creative Commons license and your intended use is not permitted by statutory regulation or exceeds the permitted use, you will need to obtain permission directly from the copyright holder.

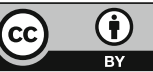

